\title{
The Relationship among Paternal Psychological Control and Adolescents' Perfectionism and Self-Esteem: A Partial Least Squares Path Analysis
}

\author{
Sabry M. Abd-El-Fattah ${ }^{1}$, Hessa Abdulrahman Fakhroo ${ }^{2}$ \\ ${ }^{1}$ Sultan Qaboos University, Muscat, Sultanate of Oman \\ ${ }^{2}$ Qatar University, Doha, Qatar \\ Email: sabryrahma@hotmail.com
}

Received February $14^{\text {th }}, 2012$; revised March $16^{\text {th }}, 2012$; accepted April $17^{\text {th }}, 2012$

\begin{abstract}
The present study investigated the relationship among paternal psychological control and adolescents' perfectionism and self-esteem. The sample included 136 father-adolescent pairings. Adolescents responded to a questionnaire tapping three aspects of perfectionism: self-oriented perfectionism, sociallyprescribed perfectionism, and concern over mistakes. Their fathers completed a questionnaire assessing their psychological control along three dimensions: direct expectations, controlling expectations, and effort approval. A path modeling showed that direct expectations and effort approval positively predicted self-oriented perfectionism. Controlling expectations negatively predicted self-oriented perfectionism and self-esteem and positively predicted socially-prescribed perfectionism. Socially-prescribed perfectionism positively predicted concern over mistakes and negatively predicted self-esteem. Adolescents' sociallyprescribed perfectionism mediated the relationship between fathers' controlling expectations and adolescents' self-esteem. Effort approval moderated the relationship between direct expectations and self-oriented perfectionism.
\end{abstract}

Keywords: Psychological Control; Perfectionism; Self-Esteem; Path Analysis

\section{Introduction}

Although the concept of parental psychological control had been identified in the 1960s (Schaefer, 1965), socialization research has only begun to systematically investigate its role in adolescents' psychosocial functioning since the mid-1990s (Barber, 1996; Barber, Olsen, \& Shagle, 1994). As such, psychological control has been defined as a characteristic of parents who pressure their adolescents to think, feel, and behave in ways they themselves dictate. Psychologically controlling parents would intrude upon the adolescent's psychological world through the use of manipulative tactics such as guilt induction, instilling anxiety, invalidation of the adolescent's perspective, and love withdrawal (Barber, 1996; Barber \& Harmon, 2002). Accordingly, parental psychological control was found to relate more strongly to internalizing (Barber, 1996) than to externalizing problems (De Kemp, Scholte, Overbeek, \& Engels, 2006), and this relationship was obtained even after controlling for the effect of other parenting dimensions, such as responsiveness and behavioral control (Barber, Stolz, \& Olsen, 2005; Soenens, Vansteenkiste, Luyten, Duriez, \& Goossens, 2005).

One important internalizing problem that has been associated with parental psychological control is adolescents' expression of low self-esteem. Rosenberg (1965) defined self-esteem in terms of a stable sense of personal worth or worthiness. More recently, Branden (2001) defined self-esteem as the experience of being competent to cope with the basic challenges of life and being worthy of happiness. According to Branden, self-esteem is the sum of self-confidence (a feeling of personal capacity) and self-respect (a feeling of personal worth). It exists as a consequence of the implicit judgment that every person does about, on one side, his/her ability to face life's challenges, that is, to understand and solve problems, and, on the other side, his right to achieve happiness or, in other words, to respect and defend his own interests and needs. In a study with two samples of Belgian college students, Soenens et al. (2005) reported that greater psychological control of both parents was associated with students' reduced self-esteem. When taking other parenting styles into account (responsiveness and behavioral control), psychological control of both parents was the only significant and negative predictor of students' self-esteem in only one sample (late adolescents).

\section{Perfectionism}

Perfectionism is characterized by striving for flawlessness and setting of excessively high standards for performance, accompanied by tendencies toward overly critical evaluations of one's behavior (Flett \& Hewitt, 2002). Consistent with the prevailing view of perfectionism as a multidimensional construct, we studied two key perfectionism dimensions. Self-oriented perfectionism (SOP; i.e., demanding perfection of oneself) involves compulsive striving, unrealistic self-expectations, and a pervasive need for perfection. Socially prescribed perfectionism (SPP; i.e., perceiving others are demanding perfection of oneself) involves exaggerated concerns over others' expectations and perceptions of others as hypercritical (Hewitt \& Flett, 1991). Hewitt and Flett's (1991) model was selected because it captures one readily observable distinction in perfectionism research: self-imposed perfectionistic strivings and expectations 
versus chronic concerns over others' expectations and evaluations (see Chang, 2006). This model also contrasts with other models involving constructs similar to SOP (e.g., Frost, Marten, Lahart, \& Rosenblate, 1990; Slaney, Rice, Mobley, Trippi, \& Ashby, 2001). In particular, Hewitt and Flett's (1991) model assesses rigid, extreme, and unrealistic strivings and expectations that do not directly reflect conscientiousness. Furthermore, Frost et al. (1990) highlighted concern over mistakes as a third form of perfectionism. It reflects a tendency to interpret mistakes as equivalent to failure and believe that one will lose the respect of others following failure.

There is sufficient evidence that both socially-prescribed perfectionism and concern over mistakes represent maladaptive forms of perfectionism associated with negative characteristics, processes, and outcomes. For example, socially-prescribed perfectionism has shown positive correlations with neuroticism and negative affect (Molnar, Reker, Culp, Sadava, \& De Courville, 2006) and with psychopathological symptoms such as anxiety, depression, somatization, and obsessive-compulsive symptoms (Hewitt \& Flett, 2004). Likewise, concern over mistakes has shown positive correlations with depressive symptom (Minarik \& Ahrens, 1996; Soenens et al., 2005), social phobia (Antony, Purdon, Huta, \& Swinson, 1998) and insomnia (Jansson-Frojmark \& Linton, 2007). However, the status of selforiented perfectionism remains equivocal. Like socially-prescribed perfectionism, self-oriented perfectionism has shown positive correlations with psychopathological symptoms (Hewitt \& Flett, 2004). However, unlike socially-prescribed perfectionism, self-oriented perfectionism has shown positive correlations with several healthy outcomes such as conscientiousness, positive affect, and goal attainment (Trumpeter, Watson, \& O'Leary, 2006).

\section{Perfectionism and Self-Esteem}

Adaptive perfectionists (e.g., self-oriented perfectionists) are characterized by setting high personal performance standards and exerting painstaking efforts. These positive characteristics are associated with feelings of personal satisfaction and achievement and consequently a secure sense of self and adaptive self-processes. They set realistic goals and maintain their ability to view themselves as successful even when their high performance standards are not fully achieved. Thus, adaptive perfectionists are more likely to maintain high levels of self-esteem (Shafran \& Mansell, 2001). Consistent with this reasoning, Parker (1997) reported that a healthy perfectionistic group (i.e., self-oriented perfectionists with moderately high level of personal standards) of early adolescents scored the highest on the Rosenberg's Self-Esteem Scale (Rosenberg, 1989) and that a dysfunctional perfectionistic group scored the lowest.

In contrast, maladaptive perfectionists (e.g., socially-prescribed and concern-over-mistakes perfectionists) would set and pursue unrealistic performance standards (Shafran \& Mansell, 2001). Across time, they would develop deep-seated feelings of inferiority, self-defeat, and ineffectiveness because they rarely feel able to attain these high performance standards (Blatt, 1995). Thus, maladaptive perfectionists are apparently mold themselves to an impossibly idealized image, making low self-esteem inevitable. Consistent with this reasoning, Soenens et al. (2005) found maladaptive perfectionism significantly and negatively related to self-esteem in two samples of Belgian college students (i.e., middle and late adolescence). Soenens and his colleagues represent maladaptive perfectionism by a composite mean score of two subscales of the Multidimensional Perfectionism Scale (Frost et al., 1990): concern over mistakes subscale and doubts about action subscale.

\section{Parental Psychological Control and Perfectionism}

Although several studies have demonstrated that adolescents' perfectionistic orientations are associated with differentiated levels of their self-esteem (Parker, 1997; Soenens et al., 2005), the genesis of such orientations are just beginning to be explored (Kawamura, Frost, \& Harmatz, 2002). Therefore, how it is that adolescents develop a perfectionistic orientation is still not entirely clear. Several researchers proposed that parents' exertion of psychological control over their adolescents may help explain adolescents' perfectionistic orientations. Those researchers argue that perfectionism and maladaptive perfectionism in particular would develop in families in which parents' approve of the adolescent's behavior is conditioned on whether the adolescent meets the parental standards for performance. When an adolescent fails to meet these standards, parents would criticize the adolescent, withdraw love, and induce guilt. As a consequence of being exposed to such psychological control, the adolescent would adopt their parents' rigid standards for performance and gradually learn to impose these standards on themselves (Flett et al., 2002). In support of this notion, Soenens et al. (2005) reported that parental psychologycal control was associated with maladaptive perfectionistic orientation in two samples of Belgian college students. When taking other parenting styles into account (responsiveness and behavioral control), parental psychological control turns out to be the strongest, and almost unique, predictor of maladaptive perfectionism. Likewise, Kawamura et al. (2002), working with a sample of Caucasian and Asian American university students, found a positive relationship between females' reports of both parents' authoritarian parenting style and cognitions associated with maladaptive perfectionism (i.e., concerns over mistakes and doubts about actions).

\section{Aim and Rationale of the Present Study}

Following on from the work of Barber (1996; Barber \& Harmon, 2002) on parental psychological control, it was postulated that fathers might attempt to induce their adolescents to adopt high performance standards through three distinct communication mechanisms: direct expectations, controlling expectations, and effort approval (see, Barber, 1996; Barber \& Harmon, 2002). A direct expectation expresses an assumption that the adolescent will do well, will meet challenges, or simply perform at a high level. A controlling expectation is defined in terms of parental need for the adolescent's high performance, and expressed as emotional contingencies that link the adolescent's striving for achievement to parental needs. Effort approval represents generalized parental approval or warmth; a factor known to facilitate intergenerational transmission effects from parents to adolescents (Zentner \& Renaud, 2007).

Numerous studies have investigated the relationship among parental psychological control and adolescents' perfectionism and self-esteem. However, these studies are limited because they only examine the relationship between two or more of these variables and as such they did not provide a complete picture of any intercausal connections among these variables. In 
an attempt to build upon and extend the findings of previous research, the present study sought to investigate the relationship between among paternal psychological control and adolescents' perfectionism and self-esteem using path analysis techniques. Probably, the greatest advantage of path analysis is that it provides a means by which the nature of the problem may be handily summarized. It requires the researcher to think about cause, particularly systems of inetercausal connections including direct and indirect effects, and provide an explicit link between prior theoretical notions of causal connections and estimates of causal impact.

Thus, a primary goal of the present study was to develop a path analysis model that could help investigate the following: 1) the extent to which adolescents' perfectionistic orientations would be predicted from parental psychological control; 2) the extend to which adolescents' self-esteem would be predicted from parental psychological control; 3) the extend to which adolescents' self-esteem would be predicted from perfectionistic orientations, and 4) whether adolescents' perfectionistic orientations would mediate the relationship between parental psychological control and self-esteem.

Figure 1 shows a hypothesized path analysis model of the relationships among paternal psychological control and adolescents' perfectionism and self-esteem. The general prediction is that direct expectations and effort approval would positively predict self-oriented perfectionism. Controlling expectations would negatively predict self-oriented perfectionism. Direct expectations and effort approval would negatively predict socially-prescribed perfectionism and concern over mistakes. Controlling expectations would positively predict sociallyprescribed perfectionism and concern over mistakes. Direct expectations, effort approval, and self-oriented perfectionism would positively predict self-esteem. Controlling expectations, socially-prescribed perfectionism, and concern over mistakes would negatively predict self-esteem.

Overall, the present study extends the existing research literature in several ways. First, most of previous studies have generally relied on participants' reports of their parents' psychological control (For an exception, see Hutchinson \& Yates, 2008). Although such reports provide insights into participants' experiences and perceptions, they may also be excessively influenced by participants' preexisting orientations toward perfectionism. For example, participants who feel that others expect them to be perfect may also feel that others are extremely demanding. Thus, the present study relied on fathers' self-report of their psychological control of their adolescents.

Second, previous studies have generally examined perfectionistic orientations within children (for an exception, see Bean \& Northrup, 2009; Soenens et al., 2005). Although childhood is considered a first crucial period for the genesis of perfectionism, Blatt (1995) recognized that important changes in the development of perfectionism take place later in life as well. Adolescence would constitute a particularly sensitive period for this because it is characterized by increases in self-consciousness

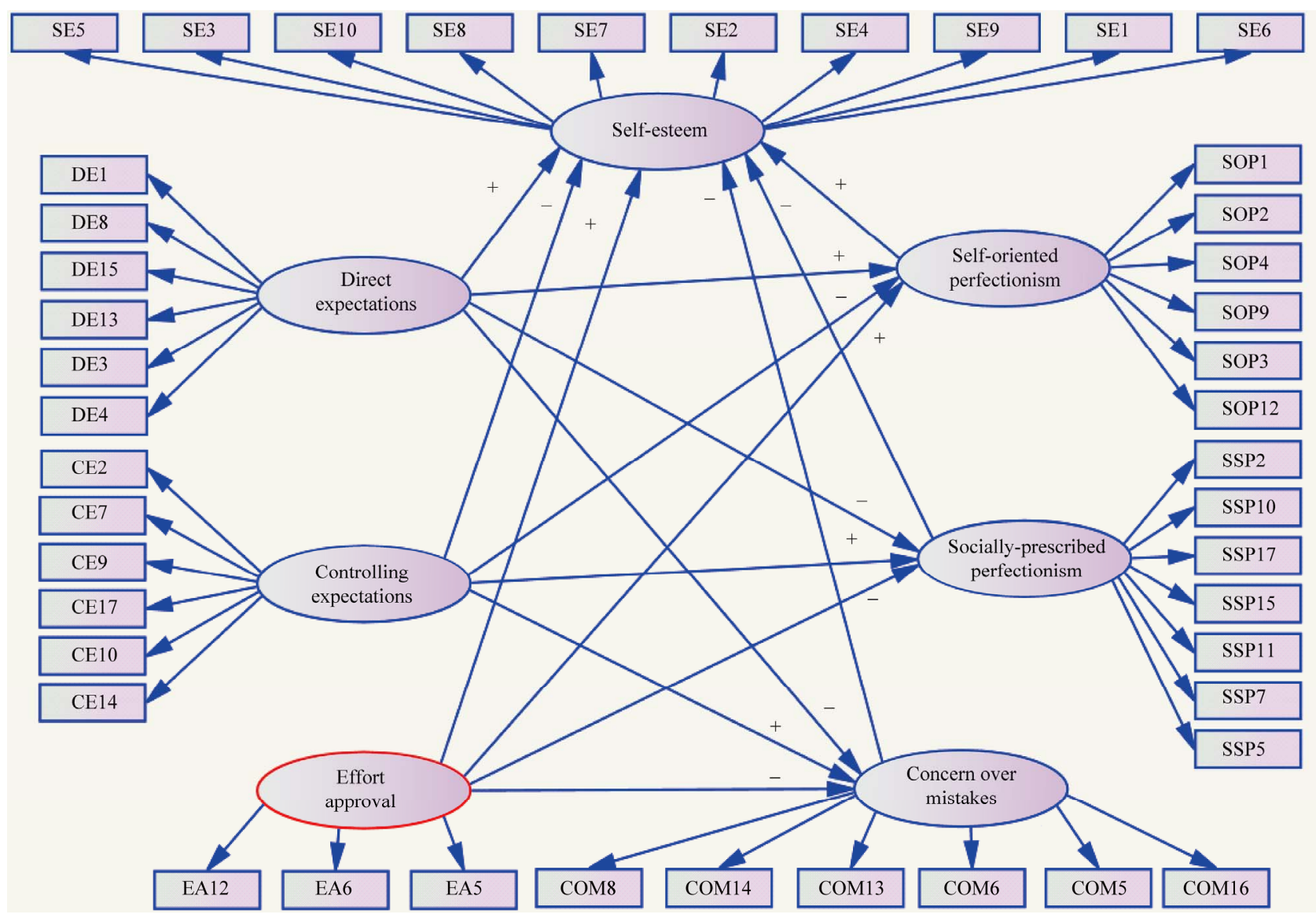

Figure 1.

Hypothesized path analysis model of the relationships among paternal psychological control and adolescents' perfectionism and self-esteem. 
and by a growing awareness of social standards and achievement expectations (Flett et al., 2002). The experience of controlling parenting at a time when adolescents are already more self-critical and sensitive to social pressures would render adolescents particularly sensitive for the development of an enduring perfectionistic orientation. Thus, the present study sought to investigate perfectionistic orientations within a sample of adolescents.

Third, previous studies have been conducted mainly in Western contexts often with scant attention for cross-cultural generalizability (For an exception, Bean \& Northrup, 2009). In other words, previous studies did not establish whether the relationship between parental psychological control and perfectionistic orientations and self-esteem, as documented for adolescents within Western contexts, is true for adolescents from non-Western cultures, where a range of parenting practices and cultural factors may lead to differences in adolescents' perfectionistic orientations and expression of self-esteem. Thus, the present study examined these relationships within a nonWestern context (i.e., Egypt).

\section{Methods}

\section{Participants and Procedures}

Subjects of the present study included 200 students from four public high schools in El-Minia governorate in North Upper Egypt. There were two metropolitan single gender schools and two rural mixed gender schools. Participant students were from second year classes and were recruited to participate in this study at a convenient time during their school hours. These students completed measures of self-oriented perfectionism, socially-prescribed perfectionism, and concern over mistakes which were administered by their class teachers. Then, these students were each given a sealed envelope to take home to their parents. This contained two copies of the Parental Goal Questionnaire which could then be collected by a research assistant. The Parental Goal Questionnaire was paired with measures of self-oriented perfectionism, socially-prescribed perfectionism, and concern over mistakes through a code number. Although mothers had been invited to participate, only 21 mothers completed the questionnaire - a number insufficient for multivariate data analysis (Stevens, 2009). Fathers returned a total of 136 questionnaires which represents a $68 \%$ response rate. Thus, the final sample consisted of 136 father-adolescent pairings. There were 73 male and 63 female students, with ages ranging from 15 to 17 years and a mean of 16.4 years (SD $=.87$ ). Ninety-five percent of the students came from intact-two parent families, $3 \%$ had divorced parents, and in $2 \%$ of the families one parent was deceased. The age of the participant fathers ranged from 38 to 55 years with a mean of 45.3 years $(\mathrm{SD}=2.6)$.

\section{Measurements}

\section{Perfectionism}

Hewitt and Flett (1991) developed the self-oriented perfectionism subscale (15 items) and the socially-prescribed perfectionism subscale (15 items) as part of the Multidimensional Perfectionism Scale (MPS, Hewitt, \& Flett, 1991). Frost, Marten, Lahart, and Rosemblate (1990) developed the concern over mistakes subscale (9 items) as part of the Frost Multidimensional Perfectionism Scale (FMPS). Students indicated their level of agreement with each item of these subscales along a four-point Likert type scale that ranged from 1 "Strongly Disagree" to 4 "Strongly Agree".

Within the present dataset, selected items from the self-oriented perfectionism subscale (6 items), socially-prescribed perfectionism subscale (7 items), and the concern over mistakes subscale (6 items) were use to assess students' perfectionistic orientations (see Appendix I). These items were chosen because they were conceptually distinguishable and they also had the highest loadings on their designate factors in the original studies by Hewitt and Flett (1991) and Frost et al. (1990). In addition, these items showed acceptable levels of reliability when used in other studies (e.g., Rice, \& Aldea, 2006; Slaney, \& Ashby, 1996). Cronbach's alpha reliability coefficients for these subscales based on the dataset of present study are shown in Table 1.

\section{Parental Goals Questionnaire}

Yates and Hutchinson (2008) developed the Parental Goal Questionnaire to assess parents' direct expectations (6 items), controlling expectations (6 items), and effort approval (3 items) (see Appendix II). Parents indicated their level of agreement with each item along a five-point Likert type scale that ranged from 1 "Strongly Disagree" to 5 "Strongly Agree". Cronbach's alpha reliability coefficients for these subscales based on the

Table 1.

Pearson's correlations, number of items, average variance extracted, composite reliability, Cronbach's alpha, and descriptive statistics.

\begin{tabular}{|c|c|c|c|c|c|c|c|c|c|c|c|c|c|}
\hline Variables & 2 & 3 & 4 & 5 & 6 & 7 & Items $^{\mathrm{a}}$ & $\mathrm{AVE}^{\mathrm{b}}$ & $\sqrt{A V E}$ & $\mathrm{CR}^{\mathrm{c}}$ & $\alpha^{\mathrm{d}}$ & Mean $^{\mathrm{e}}$ & SD \\
\hline 1. SOP & $.35^{* *}$ & $.32^{* *}$ & $.37^{* *}$ & $-.34^{* *}$ & $.32^{* *}$ & $.29^{*}$ & 5 & .62 & .79 & .74 & .72 & 2.5 & .72 \\
\hline 2. SPP & & $.34^{* *}$ & $-.25^{*}$ & $.36^{* *}$ & -.13 & $-.39^{* *}$ & 6 & .58 & .76 & .78 & .76 & 2.2 & .53 \\
\hline 3. $\mathrm{COM}$ & & & $-.33^{* *}$ & $.35^{* *}$ & .10 & -.15 & 6 & .60 & .77 & .80 & .74 & 2.3 & .41 \\
\hline 4. $\mathrm{DE}$ & & & & $.34^{* *}$ & $.30^{*}$ & $.30^{* *}$ & 6 & .53 & .73 & .76 & .73 & 2.3 & .59 \\
\hline 5. CE & & & & & $.32^{* *}$ & $-.41^{* *}$ & 6 & .64 & .80 & .79 & .80 & 3.4 & .51 \\
\hline 6. EA & & & & & & $.25^{*}$ & 3 & .55 & .74 & .75 & .77 & 2.7 & .44 \\
\hline 7. SE & & & & & & & 10 & .66 & .81 & .81 & .81 & 2.3 & .65 \\
\hline
\end{tabular}

Note: $\mathrm{SOP}=$ Self-oriented perfectionism; SPP = Socially-prescribed perfectionism; Com = Concern over mistakes; DE = Direct expectations, CE = Controlling expectations; EA = Effort approval; SE = Self-esteem; $N=136,{ }^{*} p<.05,{ }^{* *} p<.01$; ${ }^{\mathrm{a}}$ Number of items; ${ }^{\mathrm{b}}$ Average variance extracted; ${ }^{\mathrm{c}} \mathrm{Composite}$ reliability; ${ }^{\mathrm{d}} \mathrm{Cronbach}$ 's alpha reliability; ${ }^{\mathrm{e}}$ Means are expressed along a four-point Likert-type scale, $1-4$, summed across items. 
dataset of the present study are shown in Table 1.

\section{Self-Esteem}

The Rosenberg's Self-Esteem Scale (RSES, Rosenberg, 1989) was used to assess adolescents' self-esteem. This is a 10-item measure of global feelings of self-worth and self-acceptance (see Appendix III). Students indicated their level of agreement with each of the 10 items, along a four-point Likert type scale that ranged from 1 "Strongly Disagree" to 4 "Strongly Agree". Cronbach's alpha reliability coefficient for the RSES based on the dataset of the present study is shown in Table 1.

\section{Translation of the Measurements}

The adaptation of all measurements of the present study was done using the back-translation method, which is a judgmental procedure for investigating the conceptual equivalence (i.e. symmetry) of the original and translated versions, necessary for valid cross-cultural comparisons (Berry, 1980). Thereby, the authors translated all measurements from English to Arabic. Applying a back translation strategy, four qualified translators, working without referencing to the English version of the measurements, independently translated the Arabic version back to English. All the translators were accredited with the British-Egyptian Centre in El-Minia city in Egypt. Other four qualified translators independently compared the original English version of the measurements to the new English version that was translated back from Arabic, and any discrepancies were noted. This iterative process of translation and backtranslation was continued until no semantic differences were noticed between both English and Arabic versions of the measurements (Brislin, 1980).

\section{Results}

\section{Partial Least Squares Path Analysis}

The SmartPLS 2.0 M3 program (Ringle, Wende, \& Will, 2005) was used to run a partial least squares (PLS) path analysis. PLS path analysis is a statistical approach for modeling complex multivariable relationships among observed and latent variables (Chin \& Newsted, 1999). This procedure was chosen over covariance-based techniques such as LISREL because it does not hinge upon large samples and it does not make assumptions about the underlying data distribution when estimating the model parameters. In addition, PLS path analysis offers a number of advantages over LISREL in terms of the estimation of the interaction effects. This specific advantage is particularly relevant to the present study (Chin \& Newsted, 1999; Haenlein \& Kaplan, 2004).

The model analyzed in the present study contains reflective constructs only. In a reflective scheme, the set of indicators is assumed to measure a unique underlying concept (Chin \& Newsted, 1999). A PLS reflective model is usually analyzed and interpreted sequentially in two stages: 1) the assessment of the reliability and validity of the measurement model, followed by 2) the assessment of the structural model. This sequence ensures that the researcher has reliable and valid measures of constructs before attempting to draw conclusions about the nature of the relationships among constructs. The process of model fit to the data depends on an iterative procedure that fits observed measures to corresponding latent variables and then estimates the relationships among these latent variables. A least squares fit between observed and modeled parameters are computed. A best-fit solution emerges when the least squares function stabilizes between iterations (Chin, 1998; Hulland, 1999; Sellin \& Keeves, 1997).

\section{The Measurement Model}

The measurement model specifies the relationships among the observable variables and the underlying constructs. Generally, reflective constructs are assessed along the two concepts of reliability and validity (Chin, 1998; Hulland, 1999).

Reliability can be assessed both on the indicator and on the construct level. On the indicator level, the core criterion is the factor loading. Depending on the research subject and the availability of knowledge in the discipline, loadings of .5 (Chin, 1998 ) or even .4 can be accepted (Hulland, 1999). With the exception of one item in the self-oriented perfectionism subscale (loaded .27) and one item in the socially-prescribed perfectionism subscale (loaded .19), the results from the present PLS measurement model, displayed in Figure 2, show that all items loaded above .5 on their corresponding factors.

On the level of the full construct, two indices can be used: Cronbach's alpha reliability coefficient (Cronbach, 1951) and composite reliability (Werts, Linn, \& Joreskog, 1974). Both indices assume values between 0 and 1 , with higher values indicating better reliability of a construct. Authors generally find a level of .7 or higher acceptable for either index to assign reliability for a construct (Nunnally \& Bernstein, 1994). Table 1 shows acceptable levels of reliability because Cronbach's alpha and composite reliability of all constructs exceeded the minimum threshold level of .7.

Two general types of validity are considered relevant for the constructs of present PLS path model: convergent validity and discriminant validity (Hulland, 1999). The average variance extracted (AVE) is the appropriate measure of a construct convergent validity. The AVE includes the variance of its indicators captured by the construct relative to the total amount of variance, including the variance due to measurement error (Bagozzi, Yi, \& Phillips, 1991). The AVE should exceed a value of .5 to highlight a construct convergent validity (Fornell \& Larcker 1981). Table 1 shows acceptable levels of convergent validity because the AVEs of all constructs exceeded the minimum threshold value of .50 .

A necessary condition for discriminant validity of a construct is that a construct shared more variance with its own block of indicators than with another latent variable representing a different block of indicators (Hulland, 1999). According to Fornell and Larcker (1981), discriminant validity is proven if the square root of the AVE of a construct is larger than the correlation of this construct with any other construct in the model. Unfortunately, guidelines about how much larger the AVE should be larger than these correlations are not available (Fornell \& Larcker, 1981). Table 1 shows acceptable levels of discriminant validity because the square root of the AVEs of all constructs is larger than the Pearson's correlation coefficients among these constructs. Overall, these findings show that the measurement model fits the present data set adequately.

\section{The Structural Model}

The structural model describes the relationships among the 


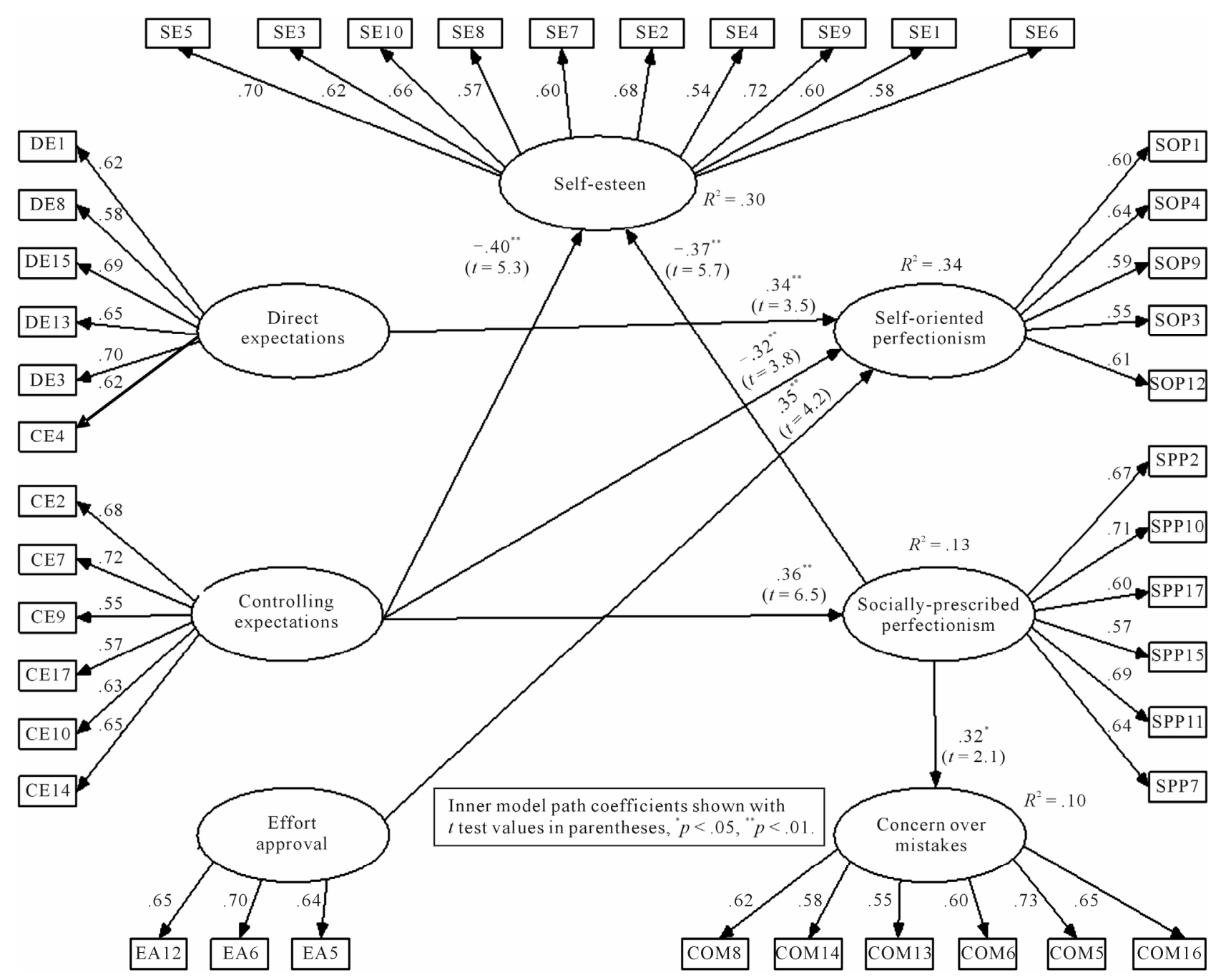

Figure 2.

Path diagram showing the relationship among paternal psychological control and adolescents' perfectionism and self-esteem.

model constructs. Unlike covariance-based procedures such as LISREL, PLS is a descriptive approach that does not hinge upon use of formal model fit statistics, which is mainly due to the assumption of distribution-free variance (Hulland, 1999). Alternatively, several non-parametrical tests can be applied to evaluate the quality of the structural model. These tests, reported in Table 2, include 1) the determination coefficients of endogenous variables $\left(R^{2}\right), 2$ ) directions and significance levels of path coefficients via bootstrapped $t$-statistics, 3) effect size $f^{2}$ (Cohen, 1988), 4) Stone-Geisser statistic $\left(Q^{2}\right.$, Geisser, 1975; Stone, 1974), and 5) Goodness of Fit index (GoF) (Tenenhaus, Esposito Vinzi, Chatelin, \& Lauro, 2005).

The $R^{2}$ can assume value between 0 and 1 . The larger $R^{2}$ is, the larger the percentage of variance explained in an endogenous variable by the exogenous variable (s) linked to it. Figure 2 shows that the $R^{2}$ value is .30 for self-esteem, .34 for selforiented perfectionism, .13 for socially-prescribed perfectionism, and .10 for concern over mistakes. Although no generalizable statement can be made about acceptable threshold values of $R^{2}$ (Stevens, 1999), these values suggest that the conceptual PLS path model, examined within the present study, is well supported by the data.
The goodness of the path coefficients estimated in PLS can be tested by means of asymptotic $t$-statistics obtained via a bootstrapping resampling procedure. Within the present analysis, the number of bootstrap samples $J$ was set to 500 to allow standard error estimates to be assayed via $t$ tests (Chin, 1998; Huland, 1999; Sellin \& Keeves, 1997).

Figure 2 shows the final PLS model, generated by eliminating non-significant paths for simplicity purposes- this is the most parsimonious descriptive model. The analysis showed that direct expectations and effort approval positively predicted selforiented perfectionism. Controlling expectations negatively predicted self-oriented perfectionism and self-esteem and positively predicted socially-prescribed perfectionism. Sociallyprescribed perfectionism positively predicted concern over mistakes and negatively predicted self-esteem. Table 2 shows a summary of the structural model statistics.

An effect size can be explored to see whether the influence of a particular independent latent variable on a dependent latent variable has substantive impact. Effect sizes were determined by a method identified by Cohen (1988) and adopted by Schroer and Herterl (2009) in PLS path models. Effect sizes of single predictors are obtained by comparing the explained 
Table 2.

PLS model path coefficients.

\begin{tabular}{|c|c|c|c|c|c|c|}
\hline Path & $\beta$ & $t$ & $\mathrm{LB} 95 \% \mathrm{Cl}^{\mathrm{a}}$ & UB $95 \% \mathrm{CI}^{\mathrm{b}}$ & $f^{2 \mathrm{c}}$ & $q^{2 \mathrm{~d}}$ \\
\hline 1. $\mathrm{DE} \rightarrow \mathrm{SOP}$ & .34 & $3.5^{* *}$ & .30 & .39 & .20 & .15 \\
\hline 2. $\mathrm{CE} \rightarrow \mathrm{SOP}$ & -.32 & $3.8^{* *}$ & -.25 & -.35 & .17 & .11 \\
\hline 3. $\mathrm{CE} \rightarrow \mathrm{SE}$ & -.40 & $5.3^{* *}$ & -.35 & -.44 & .39 & .29 \\
\hline 4. $\mathrm{CE} \rightarrow \mathrm{SPP}$ & .36 & $6.5^{* *}$ & .29 & .40 & .35 & .24 \\
\hline 5. SPP $\rightarrow \mathrm{COM}$ & .32 & $2.1^{*}$ & .25 & .36 & .20 & .13 \\
\hline 6. SPP $\rightarrow$ SE & -.37 & $5.7^{* *}$ & -.30 & -.41 & .36 & .26 \\
\hline 7. $\mathrm{EA} \rightarrow \mathrm{SOP}$ & .35 & $4.2^{* *}$ & .29 & .40 & .23 & .16 \\
\hline
\end{tabular}

Note: $N=136,{ }^{*} p<.05,{ }^{* *} p<.01 ;{ }^{\text {a }} \mathrm{LB} 95 \% \mathrm{CI}=$ Lower bound $95 \%$ confidence interval; ${ }^{\mathrm{b}} \mathrm{UB} 95 \% \mathrm{CI}=\mathrm{Upper}$ bound $95 \%$ confidence interval; ${ }^{\mathrm{c}} f^{2}=\left(R_{\text {include }}^{2}-R_{\text {exclude }}^{2}\right) /(1-$ $\left.R_{\text {include }}^{2}\right) ;{ }^{\mathrm{d}} q^{2}=\left(Q_{j \text { include }}^{2}-Q_{j \text { exclude }}^{2}\right) /\left(1-Q_{j \text { include }}^{2}\right)$.

amount of variance when a predictor is either included or excluded from the path model, that is, $f^{2}=\left(R_{\text {include }}^{2}-R_{\text {exclude }}^{2}\right) /(1$ $-R_{\text {include }}^{2}$ ). According to Cohen (1988), $f^{2}$ values of .02, .15 , and .35 signify small, medium, and large effects, respectively. Table 2 shows that the model path coefficients have moderate to high effect sizes. Noteworthy, the path coefficient from controlling expectations to self-esteem showed the largest effect size $\left(f^{2}=.39\right)$ whereas the path coefficient from controlling expectations to self-oriented perfectionism showed the smallest effect size $\left(f^{2}=.17\right)$.

The Stone-Geisser $\left(Q^{2}\right)$ statistic (Geisser, 1975; Stone, 1974) tests the predictive relevance of the model by reproducing the observed values by the model itself and its parameter estimates following a blindfold procedure. $Q^{2}>0$ implies that the model has predictive relevance whereas $Q^{2}<0$ represents a lack of predictive relevance. In general, a cross-validated redundancy $Q^{2}$ above .5 is indicative of a predictive model. The crossvalidated redundancy index assesses the capacity of the path model to predict the endogenous manifest variables indirectly from a prediction of their own latent variable using the related structural relation by cross-validation (Chin, 2010). The present PLS path model has a cross-validated redundancy index of .65, suggesting acceptable levels of predictive relevance.

As in the case of $f^{2}$, changes in $Q^{2}$ can be used to assess the relative impact of the structural model on the observed measures for each dependent latent variable: $q^{2}=\left(Q_{j \text { include }}^{2}-\right.$ $\left.Q_{j \text { exclude }}^{2}\right) /\left(1-Q_{j \text { include }}^{2}\right)$. The $q^{2}$ values of $.02, .15$, and .35 signify small, medium, and large predictive relevance of certain latent variables (Chin, 2010). Table 2 shows that the model path coefficients have moderate predictive relevance. Noteworthy, the path coefficient from controlling expectations to self-esteem shows the largest predictive relevance $\left(q^{2}=.29\right)$ whereas the path coefficient from controlling expectations to self-oriented perfectionism shows the smallest predictive relevance $\left(q^{2}=.11\right)$.

The Goodness-of-fit (GoF) index (Tenanhaus et al., 2005) takes into account the performance of both the measurement and the structural model and thus provide a single measure for the global prediction performance of the model. GOF is represented by the square root of the product of the geometric mean of the average communality (outer measurement model) and the average $R^{2}$ of endogenous latent variables. It can assume values between 0 and 1 , where a higher value represents better path model estimations. GoF criteria for small, medium, and large effect sizes would be .1, .25 and .36 respectively (Cohen, 1988). The present path model has a GOF of .35 , suggesting acceptable levels of global prediction performance.

\section{Moderating Effect}

"In general terms, a moderator is a qualitative (e.g., sex, race, class) or quantitative (e.g., level of reward) variable that affects the direction and/or strength of the relation between an independent or predictor variable and a dependent or criterion variable" (Baron \& Kenny, 1986: p. 1174). Chin, Marcolin, and Newsted (2003) proposed the product indicator approach to test for a moderating effect within the PLS path modeling approach. They suggested building the products of each indicator of the independent latent variable with each indicator of the moderator variable. To test whether the moderating effect differs signifycantly from zero, an asymptotically Student $t$ is calculated for the interaction term based on a bootstrapping technique (Chin, 2010). The SmartPLS 2.0 M3 program implements the product indicator approach to test for the moderating effect (Ringle et al., 2005).

Furthermore, the strength of the moderating effect can be assessed by comparing the proportion of variance explained, as expressed by the determination coefficient $R^{2}$, of the main effect model (i.e. the model without the moderating effect) with the $R^{2}$ of the full model (i.e. the model including the moderating effect). This idea also underlies the effect size of the moderating variable $\left(f^{2}\right)$ (Chin et al., 2003): $f^{2}=\left(R_{\mathrm{mo}}^{2}\right.$

$-R^{2}$ soderating with moderator withodel without moderator $\left(1 f^{2}\right)$ of $R_{\text {model with moderator }}^{2}$. M2 Moderating effects with effect sizes $\left(f^{2}\right)$ of .02 may be regarded as weak, effect sizes from .15 as moderate, and effect sizes above .35 as strong (Chin et al., 2003).

Within the context of the present study, when examining the relationship between controlling expectations and sociallyprescribed perfectionism, it was apparent that this relationship was not moderated by either adolescents' gender (interaction effect, $t=1.2, n s, f^{2}=.002$ ) or by level of effort approval (interaction effect, $t=1.5, n s, f^{2}=.005$ ). Similarly, the link between direct expectations and self-oriented perfectionism was not moderated by adolescents' gender (interaction effect, $t=1.1$, $\left.n s, f^{2}=.001\right)$.

However, when examining the relationship between direct expectations and self-oriented perfectionism, it was revealed that effort approval acted as a moderating factor (interaction 
effect, $\left.t=7.6, p<.01, f^{2}=.31\right)$. This moderation effect was then investigated by using the effort approval scores to divide the sample into three subgroups (low, moderate, and high, with $n$ of 44, 51, and 41, respectively). The correlations between direct expectations and self-oriented perfectionism were found to be $.06(n s), .30(p<.05)$, and $.45(p<.01)$ for these three subgroups respectively. In other words, in the relative absence of general effort approval, the impact of direct expectations upon the self-oriented perfectionism became non-significant. This is consistent with the original hypothesis that effort approval would enhance adaptive effects.

\section{Mediating Effect}

According to Baron and Kenny (1986, p. 1176), a variable may be considered a mediator "to the extent that it accounts for the relation between the predictor and the criterion". The PLS path model, presented in Figure 2, shows that the link between controlling expectations and socially-prescribed perfectionism was paralleled by a link between controlling expectations and self-esteem. This raises the possibility that socially-prescribed perfectionism underlies the link between controlling expectations and self-esteem.

In order to test the mediation effect of adolescents' sociallyprescribed perfectionism, the author employed the product of coefficients strategy (Sobel, 1982; Preacher \& Hayes, 2004, 2008). The product of coefficients strategy is preferred over Baron and Kenny's (1986) casual step approach because of two main reasons. First, causal step approach does not consider the estimate of the indirect effect, nor a standard error for this effect that might permit direct investigation of statistical significance. That is, it ignores the central question: Is the indirect effect different from zero? (Preacher \& Hayes, 2008). Second, testing the null hypothesis that indirect effect $=0$ requires one fewer hypothesis test, and thus type II error in the testing of mediation would be less likely (Preacher \& Hayes, 2004).

Within the context of the present study, mediation analysis was conducted with latent variable scores obtained in PLS analysis and then using these latent variable scores as an input for the SPSS macro provided by Preacher and Hayes (2004). The analysis showed that socially-prescribed perfectionism mediated the relationship between controlling expectations and self-esteem (indirect effect $=-.13$, Sobel $z=4.4, p<.001,95 \%$ CI: -.09: -.17$)$. The sign of the indirect effect was consistent with the interpretation that paternal controlling expectations increase adolescents' socially-prescribed perfectionism which in turn lowers adolescents' self-esteem.

\section{Indirect Effect}

According to Holmbeck (1997), two types of intervening effects can be distinguished, that is, mediated effects and indirect effects. Mediation is evident when there is an initial significant association between the independent and the dependent variable that is substantially reduced after taking the intervening variable into account. An indirect effect is evident when there is no initial relation between the independent and the dependent variable but when there is a significant indirect effect of the independent variable on the dependent variable through the intervening variable. Sobel's (1982) test can be used to assess the significance of an indirect effect.

Within the context of the present study, given the lack of a direct effect of controlling expectations on concern over mistakes, only test for an indirect effect through socially-prescribed perfectionism seem to be feasible. The analysis showed that a significant indirect effect of controlling expectations on concern over mistakes through socially-prescribed perfectionism (indirect effect $=.12$, Sobel $z=3.3, p<.01,95 \%$ CI: .08: .15). The sign of the indirect effect was consistent with the interprettation that paternal controlling expectations increase adolescents' socially-prescribed perfectionism which in turn increases adolescents' concern over mistakes.

\section{Discussion}

The PLS path analysis of the present study revealed several notable findings. First, paternal psychological control could be discriminated along three dimensions: direct expectations, controlling expectations, and effort approval. These three dimensions are meaningfully related to differences in parenting practices identified in a significant body of research within area of adolescent psychology (Lerner \& Steinberg, 2009). Most importantly, it was possible, using standard psychometric criteria, to discriminate between paternal direct expectations and controlling expectations. In context, this finding can be seen as noteworthy since it indicates that fathers, albeit unwittingly, can inform researchers of delicate differences in the manner in which they communicate fundamental attributes within their parenting repertoire (Soenens et al., 2005).

It should be noted that within the current dataset, the level of fathers' endorsement of controlling expectations was, in fact, high. This is indicated by the mean response level across the relevant items shown in Table 1 which, at a mean of 3.4 out of 4, corresponds to "Agree" on the four-point Likert type scale. However, the level of fathers' endorsement of direct expectations, at a mean 2.3 out of 4 , was low. It corresponds to "Disagree" on the four-point Likert type scale. These findings can be interpreted within the cultural context of the Arab society. Egyptian and perhaps Qatari fathers are expected to be controlling, demanding, and evaluative of their adolescents' performance. It is possible that Egyptian and Qatari fathers exerted high levels of psychological control over their adolescents because they are worried that their adolescents will turn out unsuccessful and unruly or that their adolescents will increase separation and independence from them. As such, Egyptian and perhaps Qatari fathers as well use psychological control as a means to make adolescents emotionally and psychologically dependent on them. In such enmeshed families (Green \& Werner, 1996), adolescents are not allowed to have their own lives and experiences because fathers may use control to keep family members within strictly defined family boundaries.

The second notable finding revealed via the PLS path analysis concerned the effect of paternal direct expectations and controlling expectations on adolescents' self-oriented perfectionism. Specifically, fathers' directed expectations correlated positively with adolescents' self-oriented perfectionism, however, fathers' controlling expectations correlated negatively with adolescents' self-oriented perfectionism. Similar findings were reported by Kenney-Benson and Pomerantz (2005) and more recently by Hutchinson and Yates (2008). These findings can be interpreted in terms of the ways in which parental (or at least fathers') expectations are articulated in the Arab society. In some Egyptian and perhaps Qatari families, high achievement may simply be an expected outcome (i.e., direct expecta- 
tions), apparently without attached emotional messages. This positive paternal practice can foster high performance standards within adolescents. In line with this interpretation, the analysis of the present dataset suggests the adaptive qualities of such direct, uncluttered communication patterns: the self-oriented factor, commonly documented as a key aspect of healthy perfectionism in adolescents, was high within adolescents when fathers endorsed direct expectations. In other Egyptian and perhaps Qatari families, achievement-related expectations are likely to be tied to subtle emotional cues as to parental requirements for the adolescent's high achievement (i.e., controlling expectations). These paternal emotional messages may adversely affect adolescents' strive to perform at high standards. Consistent with this reasoning, the analysis of the present dataset suggests the maladaptive qualities of these controlling expectations. The path from fathers' controlling expectations to adolescents' self-striving was a negative one, suggesting that fathers' control can work against the adolescents' intrinsic desire to succeed and perform perfectly, in a manner at variance with fathers' intentions.

The third notable finding concerned the effect of fathers' controlling expectations on adolescents' endorsement of maladaptive perfectionistic orientations. Specifically, the PLS path analysis showed that fathers' psychological control is associated with two negative adolescent's indices: directly with excessive concern with others' views (generally known as socially-prescribed perfectionism), and indirectly with the fear of making mistakes. When fathers exert psychological control over their adolescents, they may convey to adolescents that concern about what others (or at least fathers) expect is essential to please them and, thereby, to receive their love and respect. This means that others' (or at least fathers') approve of the adolescent's behavior is conditioned on whether the adolescent meets specific standards for performance. Consistent with this finding, Hutchinson and Yates (2008) reported that maternal controlling expectations were directly related to socially-prescribed perfectionism in a sample of Australian children. Other lines of research are suggestive of the possibility that parents' exertion of (psychological) control may lead children to become focused on others' expectations that they be perfect. For example, Flett, Hewitt, and Singer (1995) reported that when male college students perceived their parents as more authoritarian, they reported that others want them to be perfect, but they themselves are not oriented toward perfectionism. Likewise, Kenney-Benson and Pomerantz (2005) found that mothers who were relatively controlling and interventionist in task demands had children who reported high levels of sociallyprescribed perfectionism, together with elevated levels of depressive thinking.

Furthermore, the PLS path analysis revealed that fathers' controlling expectations is linked indirectly to adolescents' fear of making mistakes (i.e., indirect effect). Specifically, fathers' psychological control fosters adolescents' excessive concern about others which in turn links to adolescents' fear of making mistakes. This finding revealed a remarkable feature of adolescents' expressed concern about making mistakes, which is commonly seen as a crucial aspect of maladaptive perfectionism (see Flett et al., 2002). Concern over mistakes appeared to follow on from the adolescent's concern about what others expect (i.e., socially-prescribed perfectionism). Within hindsight, this appears to be a readily understood relationship: being concerned about what others expect of you is likely to result in high levels of concern about making mistakes. Consistent with this finding, Enns, Cox, and Clara (2005) found concern over mistakes have a significant positive relationship with sociallyprescribed perfectionism $(r=.63)$ in a sample of first-year medical students. Likewise, Hutchinson and Yates (2008) reported that socially-prescribed perfectionism and concern over mistakes correlated significantly and positively $(r=.48)$ in a sample of Australian children.

The fourth notable finding is that fathers' effort approval, as indexed by the endorsement of sentiments of non-contingent encouragement and support correlated positively with only one index of adolescents' perfectionistic orientation; self-oriented perfectionism. The communication of direct expectations, within the context of strong encouragement, can be interpreted as highly consistent with contemporary notions about the learning of self-regulation and the support of autonomy. Such theoretical notions highlight the positive role of adult modeling coupled with use of strong guidance cues within a supportive environment (Zimmerman, 2004). Most importantly however, is that effort approval did play an imperative role in that its relative absence apparently destroyed the relationship between fathers' direct expectations and adolescent's self-oriented perfectionism (i.e., the moderation effect). This means that if parents (or at least fathers) want their children to strive for self-set goals and achievement, it appears important that a basal level of encouragement and non-contingent support is a necessary component operating less as an energizing force but more as a moderating factor. In this case, a moderating factor can be thought to operate as a switch, or threshold, which needs to reach a certain level before other factors will function. The present dataset attests that encouragement is a fundamental background attribute within the parent-adolescent relationship, even though encouragement as an independent variable may relate directly to only one measurable adolescent outcome; self-oriented perfectionism.

The fifth notable finding concerned the role played by adolescents' socially-prescribed perfectionism as a mediator of the relationship between fathers' controlling expectations and adolescents' self-esteem (i.e., mediation effect). This finding is consistent with recent research efforts that have proposed perfectionism as a possible intervening variable in the relationship between parental psychological control and adolescents' selfesteem (e.g., Soenens et al., 2005). This finding can be interpreted within the framework of the self-determination theory (Deci \& Ryan, 2002) which proposes that environments in which parents are psychologically controlling, distant, and critical are more likely to promote the development of contingent self-worth. Many researchers argue that the tendency to experience insecure sense of self including unstable or low self-esteem stems from conditional self-regard fostered by parental psychological control (Barber \& Harmon, 2002). In support of the tenets of the self-determination theory, Bean and Northrup (2009), working with a sample of Latino adolescents, reported that fathers' psychological control was a significant negative predictor of Latino boys' self-esteem, whereas psychological control of both parents was significantly and negatively related to self-esteem among Latino girls.

Furthermore, the self-determination theory proposes that individuals with a contingent sense of self-worth are driven to continually validate their worth as people through the attainment of either internally or externally imposed criteria (i.e., socially-prescribed perfectionism). The perceived failure to 
reach the perceived expectations of others or self-imposed standards will in turn lead to a plummet in self-esteem (Deci \& Ryan, 2002). Consistent with this notion, Sorotzkin (1985) noted that for socially-prescribed perfectionists, as motivated by profound insecurity to continue attempting to gain acceptance from parents and significant others through performance accomplishments and faultless behavior, "any deviation from the perfectionistic goal is likely to be accompanied by moralistic self-criticism and lowered self-esteem" (p. 564).

To summarize, the current findings provide further insight into the dynamics which underpin the development of a perfectionistic adolescent. One important stimulant of adolescents' perfectionistic orientations is parental use of psychological control. There are suggestive evidences, within the present study, that differential paternal practices would result in differential perfectionistic orientations. Most importantly, adolescents of psychologically controlling parents would develop a socially-prescribed perfectionistic orientation which would render them vulnerable to low self-esteem. More specifically, if adolescents' perfectionism is driven by fearfulness or concern over what other people expect, then this maladaptive state is linked to levels of emotional or psychological control employed by fathers-but if adolescents' perfectionism is based upon personally held standards and self-striving tendencies, then this adaptive state appears to be linked strongly to paternal practices that combine high expectations along with moderate to strong levels of general encouragement and approval of effort.

\section{REFERENCES}

Antony, M. M., Purdon, C. L., Huta, V., \& Swinson, R. P. (1998). Dimensions of perfectionism across the anxiety disorders. Behavior Research and Therapy, 36, 1143-1154. doi:10.1016/S0005-7967(98)00083-7

Bagozzi, R. P., Yi, Y., \& Phillipps, L. W. (1991). Assessing construct validity in organizational research. Administrative Science Quarterly, 36, 421-458. doi:10.2307/2393203

Barber, B. K. (1996). Parental psychological control: Revisiting a neglected construct. Child Development, 67, 3296-3319. doi: $10.2307 / 1131780$

Barber, B. K., Bean, R. L., \& Erickson, L. D. (2002). Expanding the study and understanding of psychological control. In B. K. Barber (Ed.), Intrusive parenting: How psychological control affects children and adolescents (pp. 263-289). Washington DC: American Psychological Association. doi:10.1037/10422-009

Barber, B. K., \& Harmon, E. L. (2002). Violating the self: Parental psychological control of children and adolescents. In B. K. Barber (Ed.), Intrusive parenting: How psychological control affects children and adolescents (pp. 15-52). Washington, DC: American Psychological Association. doi:10.1037/10422-002

Barber, B. K., Olsen, J. E., \& Shagle, S. C. (1994). Associations between parental psychological and behavioral control and youth internalized and externalized behaviors. Child Development, 65, 1120-1136. doi:10.2307/1131309

Barber, B. K., Stolz, H. E., \& Olsen, J. A. (2005). Parental support, psychological control, and behavioral control: Assessing relevance across time, method, and culture. Monographs of the Society for Research in Child Development, 70 (4, Serial No. 281).

Baron, R. M., \& Kenny, D. A. (1986). The moderator-mediator variable distinction in social psychological research: Conceptual, strategic, and statistical considerations. Journal of Personality and Social Psychology, 51, 1173-1182. doi:10.1037/0022-3514.51.6.1173

Bean, R. A., \& Northrup, J. C. (2009). Parental psychological control, psychological autonomy, and acceptance as predictors of self-esteem in Latino adolescents. Journal of Family Issues, 30, 1486-1504. doi:10.1177/0192513X09339149
Blatt, S. J. (1995). The destructiveness of perfectionism. American Psychologist, 50, 1003-1020. doi:10.1037/0003-066X.50.12.1003

Branden, N. (2001). The psychology of self-esteem: A revolutionary approach to self-understanding that launched a new era in modern psychology. San Francisco: Jossey-Bass, 2001.

Brislin, R. (1986). Field methods in cross-cultural psychology. In W. J. Lonner, \& J. W. Berry (Eds.), The wording and translation of research instruments. Newbury Park, CA: Sage Publications.

Chang, E. C. (2006). Conceptualization and measurement of adaptive and maladaptive aspects of performance perfectionism. Cognitive Therapy and Research, 30, 677-697. doi: 10.1007/s10608-006-9060-7

Chin, W. W. (1998). The partial least squares approach for structural equation modeling. In G. A. Macoulides (Ed.), Modern methods for business research (pp. 295-336). Mahwah, NJ: Lawrence Erlbaum.

Chin, W. W. (2010). Bootstrap cross-validation indices for PLS path model assessment. In V. E. Vinzi, W. Chin, J. Hensler, \& H. Wold (Eds.), Handbook of partial least squares (pp. 83-97). Springer: Heidelberg. doi:10.1007/978-3-540-32827-8 4

Chin, W. W., Marcolin, B. L., \& Newsted, P. R. (2003). A partial least squares latent variable modeling approach for measuring interaction effects: Results from a Monte Carlo simulation study and an electronic-mail emotion/adoption study. Information Systems Research, 14, 189-217. doi:10.1287/isre.14.2.189.16018

Chin, W. W., \& Newsted, P. R. (1999). Structural equation modeling analysis with small samples using partial least squares. In R. H. Hoyle (Ed.), Statistical strategies for small sample research (pp. 307-341). Thousand Oaks: CA: Sage Publications.

Cohen, J. (1988). Statistical power analysis for the behavioral sciences (2 ed.). Hillsdale, New Jersey: Lawrence Erlbaum Associates.

Cronbach, L. J. (1951). Coefficient alpha and the internal structure of tests. Psychometrika, 16, 297-334. doi:10.1007/BF02310555

Deci, E., \& Ryan, R. (Eds.). (2002). Handbook of self-determination research. Rochester, NY: University of Rochester Press.

De Kemp, R., Scholte, R., Overbeek, G., \& Engels, R. (2006). Early adolescent delinquency: The role of parents and best friends. Criminal Justice and Behavior, 33, 488-510. doi: $10.1177 / 0093854806286208$

Enns, M. W., Cox, B. J., \& Clara, I. (2005). Perfectionism and neuroticism: A longitudinal study of specific vulnerability and diathesisstress models. Cognitive Therapy and Research, 29, 463-478. doi: 10.1007/s10608-005-2843-04

Flett, G. L., \& Hewitt, P. L. (2002). Perfectionism and maladjustment: An overview of theoretical, definitional, and treatment issues. In P. L. Hewitt \& G. L. Flett (Eds.), Perfectionism: Theory, research, and treatment (No. 7, pp. 5-31). Washington, DC: American Psychological Association.

Flett, G. L., Hewitt, P. L., Oliver, J. M., \& MacDonald, S. (2002). Perfectionism in children and their parents: A developmental analysis. In G. L. Flett, \& P. L. Hewitt (Eds.), Perfectionism: Theory, research, and treatment (pp. 89-132). Washington DC: American Psychological Association. doi:10.1037/10458-004

Flett, G. L., Hewitt, P. L., \& Singer, A. (1995). Perfectionism and parental authority styles. Individual Psychology, 51, 50-60.

Fornell, C., \& Larcker, D. F. (1981). Evaluating structural equation models with unobservable variables and measurement error. Journal of Marketing Research, 18, 39-50. doi:10.2307/3151312

Frost, R. O., Marten, P., Lahart, C. M., \& Rosenblate, R. (1990). The dimensions of perfectionism. Cognitive Therapy and Research, 14, 449-468. doi:10.1007/BF01172967

Geissser, S. (1975). The predictive samples reuse method with applications. Journal of the American Statistical Association, 70, 320-328.

Green, R. J., \& Werner, P. D. (1996). Intrusiveness and closenesscaregiving: Rethinking the concept of family enmeshment. Family Process, 35, 115-136. doi:10.1111/j.1545-5300.1996.00115.x

Haenlein, M., \& Kaplan, A. M. (2004). A beginner's guide to partial least squares (PLS) analysis. Understanding Statistics, 3, 283-297. doi: $10.1207 / \mathrm{s} 15328031 \mathrm{us} 03044$

Hewitt, P. L., \& Flett, G. L. (1991). Perfectionism in the self and social contexts: Conceptualization, assessment, and association with psy- 
chopathology. Journal of Personality and Social Psychology, 60, 456-470. doi:10.1037/0022-3514.60.3.456

Hewitt, P. L., \& Flett, G. L. (2004). Multidimensional Perfectionism Scale (MPS): Technical manual. Toronto, Canada: Multi-Health Systems.

Hewitt, P. L., Newton, J., Flett, G. L., \& Callander, L. (1997). Perfectionism and suicide ideation in adolescent psychiatric patients. Journal of Abnormal Child Psychology, 25, 95-101. doi:10.1023/A:1025723327188

Hofstede, G. (2001). Cultures and organizations: Software of the mind. London: McGraw-Hill.

Holmbeck, G. (1997). Toward terminological, conceptual, and statistical clarity in the study of mediators and moderators: Examples from the child-clinical and pediatric psychology literatures. Journal of Consulting and Clinical Psychology, 65, 599-610. doi:10.1037/0022-006X.65.4.599

Hulland, J. (1999). Use of partial least squares (PLS) in strategic management research: A review of four recent studies. Strategic Management Journal, 20, 195-204.

doi:10.1002/(SICI)1097-0266(199902)20:2<195::AID-SMJ13>3.0.C $\mathrm{O} ; 2-7$

Hutchinson, A. J., \& Yates, G. C. R. (2008). Maternal goal factors in adaptive and maladaptive childhood perfectionism. Educational Psychology, 28, 795-808. doi: $10.1080 / 01443410802320402$

Jansson-Frojmark, M., \& Linton, S. J. (2007). Is perfectionism related to pre-existing and future insomnia? A prospective study. British Journal of Clinical Psychology, 46, 119-124. doi:10.1348/014466506X158824

Kawamura, K. Y., Frost, R. O., \& Harmatz, M. G. (2002). The relationship of perceived parenting styles to perfectionism. Personality and Individual Differences, 32, 317-327. doi:10.1016/S0191-8869(01)00026-5

Kenney-Benson, G. A., \& Pomerantz, E. M. (2005). The role of mothers' use of control in children's perfectionism: Implications for the development of children's depressive symptoms. Journal of Personality and Social Psychology, 73, 23-46.

Lerner, R. M., \& Steinberg, L. (2009). Handbook of adolescent psychology: Individual basis of adolescent development. Hoboken, $\mathrm{NJ}$ : John Wiley \& Sons.

McCreary, B. T., Joiner, T. E., Schmidt, N. B., \& Ialongo, N. S. (2004). The structure and correlates of perfectionism in African American children. Journal of Clinical Child and Adolescent Psychology, 33, 313-324. doi:10.1207/s15374424jecp3302 13

Minarik, M. L., \& Ahrens, A. H. (1996). Relations of eating and symptoms of depression and anxiety to the dimensions of perfectionism among undergraduate women. Cognitive Therapy and Research, 20, 155-169. doi:10.1007/BF02228032

Molnar, D. S., Reker, D. L., Culp, N. A., Sadava, S. W., \& DeCourville, N. H. (2006). A mediated model of perfectionism, affect, and physical health. Journal of Research in Personality, 40, 482-500. doi:10.1016/j.jrp.2005.04.002

Nunnally, J. C., \& Bernstein, I. H. (1994). Psychometric theory (3 ed.). New York: McGraw-Hill.

Parker, W. D. (1997). An empirical typology of perfectionism in academically talented children. American Educational Research Journal, 34, 545-562. doi: $10.3102 / 00028312034003545$

Preacher, K. J., \& Hayes, A. F. (2004). SPSS and SAS procedures for estimating indirect effects in simple mediation models. Behavior Research Methods, Instruments, and Computers, 36, 717-731. doi: 10.3758/BF03206553

Preacher, K. J., \& Hayes, A. F. (2008). Asymptotic and resampling strategies for assessing and comparing indirect effects in multiple mediator models. Behavior Research Methods, 40, 879-891. doi: 10.3758/BRM.40.3.879

Rice, K. G., \& Aldea, M. A. (2006). State dependence and trait stability of perfectionism: A short-term longitudinal study. Journal of Counseling Psychology, 53, 205-213. doi:10.1037/0022-0167.53.2.205

Ringle, C. M., Wende, S., \& Will, A. (2005). SmartPLS 2.0 M3. Hamburg: University of Hamburg.

Rosenberg, M. (1965). Society and the adolescent self-image. Princeton, NJ: Princeton University Press.

Rosenberg, M. (1989). Society and the adolescent self-image. Revised edition. Middletown, CT: Wesleyan University Press.

Schaefer, E. S. (1965). A configurational analysis of children's reports of parent behavior. Journal of Consulting Psychology, 29, 552-557. doi: $10.1037 / \mathrm{h} 0022702$

Schroer, J., \& Hertel, G. (2009). Voluntary engagement in an open web-based encyclopedia: Wikipedians, and why they do it. Media Psychology, 12, 96-120. doi:10.1080/15213260802669466

Sellin, N., \& Keeves, J. (1997). Path analysis with latent variables. In J. P. Keeves (Ed.), Educational research, methodology, and measurement: An international handbook (pp. 633-640). Oxford, UK: Pergamon.

Shafran, R., \& Mansell, W. (2001). Perfectionism and psychopathology: A review of research and treatment. Clinical Psychological Review, 21, 879-906. doi:10.1016/S0272-7358(00)00072-6

Slaney, R. B., \& Ashby, J. S. (1996). Perfectionists: Study of a criterion group. Journal of Counseling and Development, 74, 393-398. doi:10.1002/j.1556-6676.1996.tb01885.x

Slaney, R. B., Rice, K., Mobley, M., Trippi, J., \& Ashby, J. (2001). The revised almost perfect scale. Measurement and Evaluation in Counseling and Development, 34, 130-145.

Sobel, M. E. (1982). Asymptotic confidence intervals for indirect effects in structural equations models. San Francisco: Jossey-Bass.

Soenens, B., Vansteenkiste, M., Luyten, P., Duriez, B., \& Goossens, L. (2005). Maladaptive perfectionistic self-representations: The mediational link between psychological control and adjustment. Personality and Individual Differences, 38, 487-498.

doi:10.1016/j.paid.2004.05.008

Sorotzkin, B. (1985). The quest for perfection: Avoiding guilt or avoiding shame? Psychotherapy, 22, 564-571. doi: $10.1037 / \mathrm{h} 0085541$

Stevens, J. (1999). Intermediate statistics: A modern approach (2 ed.). New York. Routledge

Stone, M. (1974). Cross-validation choice and assessment of statistical predictions. Journal of the Royal Statistical Society, 36, 111-133.

Tenenhaus, M., Esposito Vinzi, V., Chatelin, Y. M., \& Lauro, C. (2005). PLS path modeling. Computational Statistics and Data Analysis, 48, 159-205. doi:10.1016/j.csda.2004.03.005

Trumpeter, N., Watson, P. J., \& O’Leary, B. J. (2006). Factors within multidimensional perfectionism scales: Complexity of relationships with self-esteem, narcissism, self-control, and self-criticism. Personality and Individual Differences, 41, 849-860. doi:10.1016/j.paid.2006.03.014

Werts, C. E., Linn, R. L., \& Joreskog, K. G. (1974). Interclass reliability estimates: Testing structural assumptions. Education and Psychological Measurement, 34, 25-33. doi:10.1177/001316447403400104

Zentner, M., \& Renaud, O. (2007). Origins of adolescents' ideal self: An intergenerational perspective. Journal of Personality and Social Psychology, 92, 557-574. doi:10.1037/0022-3514.92.3.557

Zimmerman, B. J. (2004). Sociocultural influence and student's development of academic self-regulation: A social-cognitive perspective. In D. M. McInerney, \& S. V. Etten (Eds.), Big theories revisited (pp. 139-164). Greenwich, CT: Information Age. 


\section{Appendix I. Perfectionism}

\section{Self-Oriented Perfectionism}

1) It is very important that I am perfect in everything I attempt.

2) I strive to be perfect as I can.

3) It makes me uneasy to see an error in my work.

4) I am perfectionistic in setting my goals.

5) I set very high standards for myself.

\section{Socially-Prescribed Perfectionism} I do.

1) The people around me expect me to succeed in everything

2) Success means that I must work even harder to please others.

3) My family expects me to be perfect.

4) People expect nothing less than perfection from me.

5) People expect more from me than I am capable of giving.

6) I find it difficult to meet others' expectations of me.

\section{Concern over Mistakes}

1) If I fail partly, it is as bad as being a complete failure.

2) People will probably think less of me if I make a mistake.

3) I should be upset if I make a mistake.

4) If I do not do well all the time, people will not respect me.

5) If I fail at work/school, I am a failure as a person.

6) The fewer mistakes I make, the more people will like me.

\section{Appendix II. Parental Goals Questionnaire}

\section{Direct Expectations}

1) It is important to me that my child sets higher goals than most people.

2) I have high standards for my child's performance at school.

3) It is important for me that my child be competitive in academic pursuits.

4) I set high standards for my child.
5) I feel it is important to know how my child is performing compared with their peers.

6) School work should consistently challenge and extend my child.

\section{Controlling Expectations}

1) I often feel frustrated because my child does not meet my goals.

2) Only outstanding performance is good enough in our family.

3) I am fearful of my child making mistakes.

4) I have higher expectations for my child's future than my child has.

5) I still praise my child's efforts even if they have not met my expectations. (Reverse scored)

6) I hardly ever feel that what my child does is good enough.

\section{Effort Approval}

1) I would be pleased if my child did their best, but did not get the top mark in a test.

2) I think trying hard is more important than being the best.

3) My child's happiness is more important to me than his or her academic success.

\section{Appendix III. Rosenberg's Self-Esteem Scale}

1) I feel that I'm a person of worth, at least on an equal plane with others.

2) I feel that I have a number of good qualities.

3) All in all, I am inclined to feel that I am a failure.

4) I am able to do things as well as most other people.

5) I feel I do not have much to be proud of.

6) I take a positive attitude toward myself.

7) On the whole, I am satisfied with myself.

8) I wish I could have more respect for myself.

9) I certainly feel useless at times.

10) At times I think I am no good at all. 